society, the powers of our antihectic powder of curing, as if by miracle, the hectic fever and the swelled bellies of children in this town, would have remained a secret while I lived."

\section{CASE OF CÆSAREAN SECTION.} BY J. W. ROE, M.D., Ellesmere.

Mollities Ossium: Great Deformity of Pelvis both at Brim and Outlet: Operation on the fourth day of Labour: Death on fifth day after Operation: Child still Living.-H. S., aged 35, of very cachectic appearance, and deeply marked by small-pox, some years ago had been an inmate of the Ellesmere Union Workhouse, when she was confined to her bed for nearly four years, suffering from mollities ossium. Three years last November, and some time subsequently to leaving the Workhouse, she married. She has miscarried twice since her marriage. On Saturday, January 8 th, I870, at 9 P.M., I was sent for to see her, the messenger stating that she had been in labour since $3 \mathrm{~A} . \mathrm{M}$. of the morning of that day. A midwife was in attendance. On my arrival, I was informed that the liquor amnii had been discharged at the commencement of the labour. The uterine action appeared to be strong and frequent. Examination per vaginam disclosed the following conditions. The rami of the ischia and pubes approximated so closely as not to allow of the finger being passed between them. The space, reaching from the posterior border of the tuberosities of the ischia to the coccyx, and bounded laterally by the sacro-ischiatic ligaments, would not admit my two forefingers placed transversely. The coccyx was much curved forwards. With considerable difficulty and pain to the woman, I reached the os uteri and could just introduce the tip of my finger. I could not detect any presentation. I requested the assistance of Dr. Moorhouse of this town, who, on examination, verified the condition above described. Subsequently, by pushing back the perinæum and vagina, I succeeded in touching the sacral promontory, which was felt to be much projected forwards, but failed to reach the presenting part of the fotus. On further consultation, and having regard to the serious nature of the case, and the difficulty of performing any operation that might be deemed necessary in a dark hovel only a few feet square, we advised her removal to the Union Workhouse. I gave her forty minims of tincture of opium, and left at $\mathbf{2} 2$ P. M.

She was taken to the Workhouse at Io A.M. on the 9th. She had suffered little pain since taking the laudanum, but had vomited frequently. There were now no pains, uterine action being suspended. $\mathrm{Mr}$. Whitfield joined us in consultation, and examined the patient. $\mathrm{He}$ was of opinion that we could do nothing at present ; and, in the absence of all uterine action, any interference was out of the question. 4 P. M. No change had occurred.

January roth. She had passed a tolerably comfortable night; no pains. She had taken beef-tea, milk, etc. She was allowed to sit up and to walk about.

January I Ith. She had slept during the night. A dose of castor-oil was given. -5 P.M. She complained of pains returning. There was no change in the state of the os uteri.

January 12th, 9 A.M. The os uteri was soft and dilatable, but otherwise not changed; pulse, I20.-5 P.M. The pains had been strong and frequent since the morning, and the os uteri was slightly dilated : no presentation could be felt. Dr. Moorhouse and I discussed the advisability of waiting for further time before deciding upon any operation. We decided upon waiting, if possible, until the following morning. At 9 P.M., an urgent request was sent to me to go to her. Dr. Moorhouse and Mr. Whitfield accompanied me. Uterine action was now very constant and strong. Our examination was carefully repeated, but without disclosing any further change in the condition of the parts, except that there was increased dilatation of the os. In spite of the powerful uterine contractions, the presenting part of the fœtus failed to enter the pelvic brim. Stethoscopic examination had been made several times, and no placental sound detected, though the fotal heart was audible on one occasion. The pulse was now very rapid. After further consultation, the Cæsarean section was advised, and at once acquiesced in by the woman and her husband. Arrangements were made accordingly; and, the patient being placed upon her back on a table, I first proceeded to introduce a catheter, and found it exceedingly difficult to do this in the usual way, in consequence of the woman being unable to separate her thighs to the required extent. Chloroform was administered by Dr. Moorhouse; and, when the patient became insensible, I made an incision about six inches in length along the course of the linea alba, commencing two inches above the umbilicus. The peritoneum was opened to the same extent. An incision of nearly the same length was made in the uterine walls, and immediately the placenta was dis. closed to view, and a gush of blood took place. I at once removed the placenta, and afterwards a small but healthy living female child, the head of which was presenting above the pelvic brim. The uterus instantly contracted and descended into the pelvis; and at the same moment a considerable portion of the ileum escaped through the $a b$ dominal incision. 'This being replaced, the edges of the wound were brought together, and Dr. Moorhouse introduced three wire and three silk sutures, which effectually retained them in apposition. Dr. Richardson's styptic colloid was freely applied over the cut edges, and a pledget of lint, soaked in the same fluid; and over all, a broad bandage. One grain of opium was given immediately, and ordered to be repeated in four hours. In three hours she slept.

January I $3^{\text {th, }} 9$ A.M. She had passed a fairly comfortable night, sleeping three hours at a time. I passed a catheter in the obstetric position and drew off half a pint of high coloured urine. The lochial discharge was free and abundant per vaginam. She expressed herself as feeling comfortable, but coughed a good deal; pulse 120. The child was doing well. - 9 P.M. She was going on the same, and had taken liquid nourishment freely.

January I4th, 9 A.M. She had slept at intervals; respiration was still quickened; pulse, I30; the cough harassed her; mucous rales were audible over the chest; the belly was somewhat tumid; she had no pain on pressure; she had passed urine freely. -9 P. M. Pulse, 146; respiration, 36 ; temperature, I00.5. The expectoration was thick and difficult of removal, and the cough frequent. She was ordered to have a mixture containing ammonia, morphia, cinchona, and chloric ether. Food had been taken well during the day.

January I $5^{\text {th, }} 9$ A.M. She had passed a bad night, vomiting constantly. The urine passed freely. Mucous râles were audible over the upper part of the chest on both sides anteriorly, and over the base of the right lung behind. Pulse, 140 ; respiration, 42 ; temperature, 99. 2. Beef-tea, brandy, and milk, had been taken, but vomited. -8 P. M. She had vomited at intervals during the day. She refused beef-tea and milk, but took a little brandy. The rales were spreading over the chest. She complained of pain across the belly. A copious loose motion had been passed during the day. Pulse very rapid; respiration, 42 ; temperature, 99.2. She had not slept. The lochial discharge had been abundant and healthy since the operation, but was now somewhat offensive; the breasts had also secreted milk. There was considerable tympanitis ; and at times the abdominal pain was much aggravated. Two-thirds of a grain of acetate of morphia were injected subcutaneously.

January I6th, 9 A.M. She had slept for several hours; her breathing was easier; she had vomited once only; pulse, 130; respiration, 30 ; temperature, 98.8. The hypodermic injection was repeated. -7 P.M. She had taken nourishment fairly. The chest was loaded with mucus, which she was unable to expectorate. The lochia continued, but were very dark and offensive. Pulse, 140; respiration, 36 ; temperature, 100.5. Several loose motions had been passed during the day. The hypodermic injection was repeated. She died at 2 A.M., rather suddenly.

At the post mortem examination, which was made on the I8th, the following conditions were noticed.

The bones of the lower extremities were much bent and deformed, as were also the arms, which were remarkably short. The fingers were misshapen and knobbed. The height of the body, when the woman was living, was a little over four feet. There was no attempt at union throughout the entire length of the incision. The abdominal cavity contained some bloody serum. The intestines were glued to each other and to the abdominal walls with recent lymph. The uterus was contracted. The edges of the uterine incision were everted, but the cut surfaces were glued together. The pelvis gave the following measurements at the brim. The antero-posterior, from the symphysis pubis to the sacral promontory, was $3 \frac{3}{8}$ inches; the transverse diameter, $4 \frac{1}{8}$ inches. The horizontal rami of the pubes being approximated from before backwards, measured across at their junction with the iliac bones exactly I inch ; and from this point backwards to the promontory of the sacrum, $2 \frac{1}{2}$ inches, which represented the space available for the passage of the head. The outlet of the pelvis presented the following appearances and measurements. The rami of the ischia and descending rami of the pubes were closely approximated, and the tuberosities of the ischia were only separated to the extent of $I \frac{1}{2}$ inches at their greatest point of divergence. ; from the tip of the coccyx to the symphysis pubis was 3 inches; and from the tip of the coccyx to an imaginary line drawn from one tuber ischii to the other, $\mathbf{I} \frac{1}{8}$ inch; and this measurement represents the available space for extraction of the fotus at the pelvic outlet.

It seems to me that the double deformity (if I may so call it) constituted the great obstacle in attempting delivery per vias naturales. If the head could have entered the pelvis, it would have been possible to extract the fotus piece-meal through the small outlet. On the 
other hand, a larger outlet would have permitted the application of instruments to the head above the contracted brim; but the combination of difficulties rendered it impossible to introduce instruments with safety to the woman, inasmuch as the hand could not be used to guide them ; moreover, it was impossible to make out the presentation by the usual means. I may add, that up to the present time the child has done well.

\section{MUSEUM NOTES.}

\section{THE RICHMOND HOSPITAL MUSEUM, DUBLIN.}

Amongst the treasures of this Museum are the original cast and drawings, by Dr. R. W. Smith, illustrating a case of Dislocation of the Foot forwards. The case is given in detail in the catalogue by Dr. Smith. One drawing represents the patient as he stood at the time of the accident, whilst another shows the character of the deformity. The dislocation was caused by a hogshead falling against the knee whilst the foot was fixed. It remained unreduced. In Mr. Holthouse's article in Holmes's System of Surgery, but one instance of this form of dislocation is mentioned ; * it was recorded by M. Parise, and is quoted from Malgaigne. It also remained unreduced. Dr. Smith's patient did not come under his care until seven months after the accident. Dr. Smith has published the case in detail in the Dublin Quarterly fournal, vol. xiii, p. 465 , from which we abstract the following.

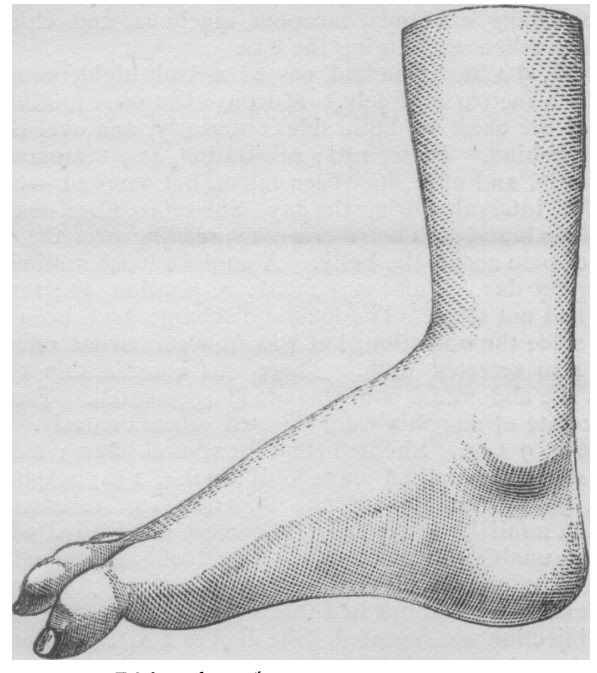

Dislocation of the whole foot forwards.

The dorsum of the foot in front of the tibia was exactly an inch longer than upon the sound side. The external malleolus was placed seven inches behind the extremity of the fifth toe, and one in front of the tendo Achillis. On the opposite foot, the measurements were six inches and two respectively. The lower end of the tibia projected markedly backwards. The projection of the heel was lost. The antero-posterior arch of the foot was increased, so that the plantar region was fully an inch less in extent than upon the opposite side. The front of the upper surface of the astragalus was exposed to the touch. It must be noted that the malleoli had altered in position with reference to the tarsus. At the time of the accident, the anterior part of the foot was above the level of the heel, so that the articular pulley of the astragalus was directed from before downwards and backwards, whilst the knee was not only considerably bent, but was advanced before the ankle. At the time the man came under Dr. Smith's observation, the foot was colder than natural, and the patient was unable to throw the weight of his body on it, and complained of numbness and distressing tingling sensations in it. There was a tendency to rest on the outer margin. The ankle was fixed at a right angle, and could neither be flexed nor extended. There was not such an extent of the astragalus exposed as would have been expected. The inner malleolus was obscured, and "altered from its natural form".

* Although M. Parise's case is quoted as one of "dislocation of the foot for wards," the narrative makes it quite clear that it was not precisely such. It seems evident that it was a dislocation of the astragalus from the rest of the tarsus. The astragalus, still in connection with the bones of the leg, passed backwards and pressed against the tendo Achillis. Thus, it seems very probable that Dr. Smith's case may be unique in surgical records. A duplicate of the cast ought to be obtained for our London College of Surgeons Museum.

\section{SPECIAL CORRESPONDENCE.}

\section{PARIS. \\ [FROM OUR OWN CORRESPONDENT.]}

Paris, Monday, 2oth June, 1870.

1. Last Week's Small-poxMortality.-2. Animal and Arm-to-Arm Vaccination.-3. Gratuitous Work for Country Doctors. -4. Medical Men in France are cheaply educated and heavily taxed.-5. Health of the Emperor.

LAST WeEK's SMALL-POX MORTALITY. - The mortality from smallpox having showed a decline in the two weeks ending respectively on the 3 rd and $1 \mathrm{rth}$ June, hopes naturally arose that the pestilence was fairly on the wane. These hopes have been dispelled by the bulletin issued on Saturday evening by the authorities of the Préfecture. That document tells us that during the week ending Friday, 18th June, $23^{8}$ persons died in Paris from small-pox. This is the highest mortality from small-pox which has been announced since the beginning of the epidemic ; the next highest weekly mortality announced was that for the week ending $27^{\text {th }}$ May, in which 218 deaths from small-pox were reported.

Subjoined is a note of the total and the small-pox mortality as officially declared for the last four weeks.

$$
\begin{aligned}
& \text { Week ending Friday, } 27 \text { May. .......... } 218 \text {........... } 1254
\end{aligned}
$$

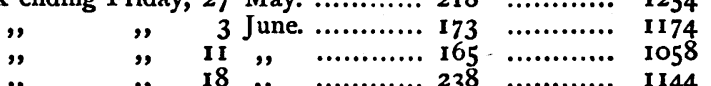

It has been vaguely said or suggested that the increase in last week's small-pox mortality is only apparent, and that it arises from the hospital deaths being for the first time included in the bulletin issued by the Préfecture. Be that as it may, several newspapers of to-day and yesterday - on whose authority does not appear-announce that 88 of the 238 deaths from small-pox which occurred in Paris during the week ending on the 18 th occurred in hospitals. The municipal authorities are still reticent as to the elements of their weekly mortuary bulletin; and the Santé Publique still says: "Of what value are the mortuary bulletins?" The official reticence is quite remarkable, and much remarked upon. It reminds one of a very juvenile philosopher who (legend tells us) accepted a daily drubbing from his scholastic chief for always refusing to enunciate the letter A. A condisciple having asked the recalcitrant individual why the drubbing was preferred to the pronouncing of the letter A, received this reply: "If I say A, he'll make me say B, and C, and all the letters of the alphabet !" M. Husson is most probably a philosopher of the samesschool. He fears-not unnaturally - that if he disclose one of the mysteries of his statistical laboratory, he might seriatim be asked fifty questions about the hospitals of Paris, to some of which it might be exceedingly troublesome to prepare replies. The conclusion of the passage in the Sante Publique to which I have just referred is contained in its impression of the $16 \mathrm{th}$, and is to the following effect: "In some hospitals, the number of small-pox patients is increasing - as for example at the Hôpital des Enfants Malades and the Salpêtrière. Yesterday, there were in the latter Hospital 120 cases of small-pox ; and, as a rule, they were cases of formidable type: Que valent donc les bulletins de d'cès?"

"Animal" and ARM-To-Arm Vaccination.-" My darling little heifer, thou still hast a great deal of work to do !" Figaro must have his fun out of everything, not excepting the sanctities of religion and morals, the most hideous abominations of wickedness, and even the loathsome promenade of pestilence now passing before our eyes. For this " bad taste" he is often blamed; but is he blameworthy? He knows that there is only one way by which the French public can be made to buy and read his paper in thousands and tens of thousands, and that is by transforming everything-truth itself-into a joke. Here is the jocular paragraph in which Figaro yesterday announced the increase in the mortality from small-pox.

"Génisse, ma mie, tu as encore bien à faire! Cette semaine, l'horrible variole n'a pas fait moins de 238 victimes : 150 en ville et 88 dans les hôpitaux. C'est, depuis le commencement de l'épidémie, la mortalité la plus considérable. Si cela continue, d'ici peu, la moitié de la population parisienne sera vetuillotie."

The public, including Figaro, ought to know that there is a great deal of vaccination work to do, and that the heifer cannot do it. Even the partizans of animal vaccination now armit that it is exceedingly difficult to get virus from the heifer "to take"; and the tens of thousands at present unprotected might have been protected by cow-pox resulting from Jennerian lymph, had the late frenzy to be vaccinated been met 